\title{
Short-term slow slip events along the Ryukyu Trench, southwestern Japan, observed by continuous GNSS
}

Takuya Nishimura

\begin{abstract}
In this study, short-term slow slip events (SSEs) along the Ryukyu Trench, southwestern Japan were systematically examined using continuous global navigation satellite system (GNSS) data. In total, 130 probable and 93 possible short-term SSEs in the moment magnitude $\left(M_{w}\right)$ range of 5.6 to 6.8 were identified from January 1997 to November 2013 by GNSS time series offset monitoring and elastic dislocation modeling with a rectangular fault located on the subducting Philippine Sea Plate. The detected short-term SSEs were found to have a variety of characteristic recurrence intervals, magnitudes, durations, and coincidental seismic activities. Short-term SSEs without identified low-frequency earthquakes (LFEs) and low-frequency tremors (LFTs) were found to be common along the Ryukyu Trench. The total slip distributions and SSE numbers were heterogeneous and mostly between 10 and $60 \mathrm{~km}$ in depth. Although shallow (depth $\leq 20 \mathrm{~km}$ ) short-term SSEs have never been detected along the Nankai Trough, it was notable that such SSEs often occur on the shallow plate interface along the Ryukyu Trench. This may be related to the incomplete interplate locking estimated by various geodetic studies. A band of short-term SSEs in the 20 to $40 \mathrm{~km}$ depth range extends from west Shikoku through the Bungo Channel to mid-Kyushu and then fades away around the subducted Kyushu-Palau Ridge. SSEs with accompanying LFEs and LFTs were found to be limited to western Shikoku and the Bungo Channel. We found several distinctive clusters of short-term SSEs, in addition to a cluster previously identified in the Yaeyama Islands. The study also identified a cluster northeast of Kikaijima consisting of 20 repeated SSEs at depths in the vicinity of $10 \mathrm{~km}$ near the trench where the Amami Plateau subducts, as well as another cluster southeast of Okinawa Island consisting of $29 M_{w} \leq 6.0$ SSES. The results suggest that the distribution of short-term SSEs, as well as that of large earthquakes, is affected by the topography of the subducting plate.
\end{abstract}

Keywords: Slow slip event (SSE); Slow earthquakes; Ryukyu Trench; Nankai Trough; GNSS

\section{Background}

Slow slip events (SSEs) have been observed in subduction zones worldwide by geodetic instruments (cf., Schwartz and Rokosky 2007; Beroza and Ide 2011; Nishimura et al. 2014). Because dense geodetic networks have revealed numerous repeated SSEs in the circum-Pacific seismic belt (e.g., Obara and Hirose 2006; Szeliga et al. 2008; Wallace et al. 2012; Ozawa et al. 2013; Ozawa 2014), they have come to be regarded as playing an important role in releasing strain in subduction zones. Reported SSEs have shown wide variations in source duration, magnitude, and

Correspondence: nishimura.takuya.4s@kyoto-u.ac.jp

Disaster Prevention Research Institute, Kyoto University, Gokasho, Uji, Kyoto 611-0011, Japan depth, and we do not yet fully understand which condition(s) controls their behaviors.

Slow earthquakes, including SSEs, low-frequency earthquakes (LFEs), low-frequency tremors (LFTs), and very low frequency earthquakes (VLFEs) along the Nankai Trough, which is located southwest of Japan, have been investigated by numerous researchers (e.g., Hirose et al. 1999; Ozawa et al. 2001, 2013; Obara 2002, 2010, 2011; Ito et al. 2009). Non-volcanic deep LFTs and LFEs occur in a narrow band at depths of 30 to $45 \mathrm{~km}$, presumably on the plate interface (Obara 2002, 2010). In this research, we eliminate the distinctions between LFT and LFE distributions because deep LFTs consist of deep LFEs (Shelly et al. 2007). Numerous LFEs form a band in western Shikoku and the Bungo Channel (Figure 1), and short-term SSEs

\section{实}

(C) 2014 Nishimura; licensee Springer. This is an Open Access article distributed under the terms of the Creative Commons Attribution License (http://creativecommons.org/licenses/by/4.0), which permits unrestricted use, distribution, and reproduction in any medium, provided the original work is properly credited. 


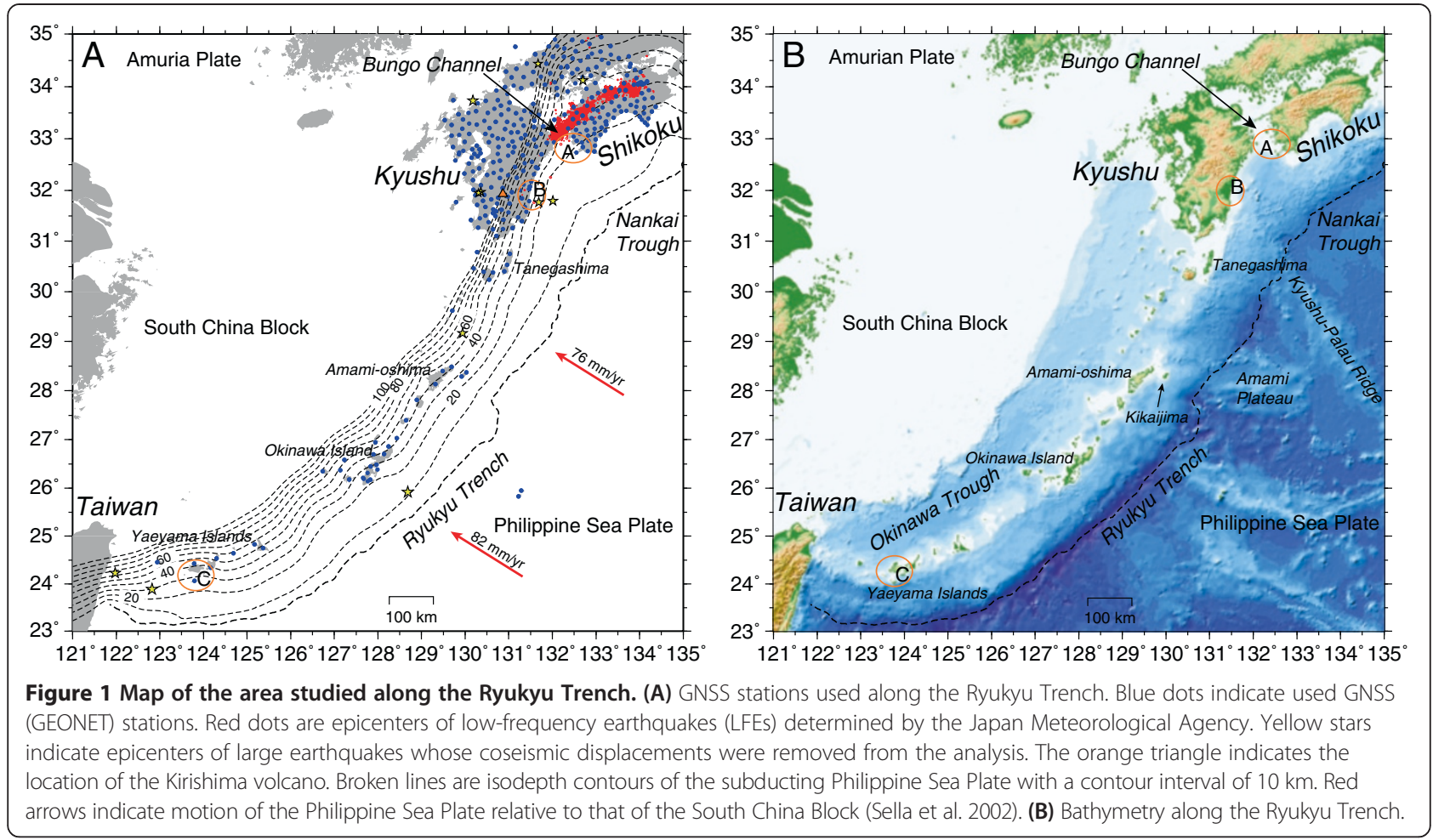

with durations ranging from a few days to a few weeks often occur in the LFT band of these regions (Obara and Hirose 2006; Sekine et al. 2010; Nishimura et al. 2013). Short-term SSEs accompanying LFTs are called episodic tremor and slip (ETS) events (Rogers and Dragert 2003) and repeat at an interval of approximately 6 months in western Shikoku, while long-term SSEs with durations of several months to a year occur in the Bungo Channel and western Shikoku (Hirose et al. 1999; Kobayashi 2010; Ozawa et al. 2013). Long-term SSEs with moment magnitude $\left(M_{w}\right)$ ranges of 7.0 to 7.1 were observed by global navigation satellite system (GNSS) in the Bungo Channel (Figure 1, region A) in 1997, 2003, and 2010. These longterm SSEs occur up-dip of the short-term SSEs at depths of 20 to $30 \mathrm{~km}$ if they both occur on the plate interface. In contrast, studies on slow earthquakes are very limited along the Ryukyu Trench, which is the southwest extension of the Nankai Trough. LFEs near the plate interface are also rare in Kyushu (Yoshioka et al. 2008; Yabe and Ide 2013), and the Japan Meteorological Agency (JMA) has not identified any LFEs from Tanegashima to the Yaeyama Islands along the Ryukyu Trench (Figure 1). However, recent studies have revealed that numerous VLFEs occur along the Ryukyu Trench (Ando et al. 2012; Asano et al. 2013), and while this occurrence frequency suggests frequent SSEs occurrences as well, SSEs have only been reported in two cases. The first involved short-term SSEs that occurred in the Yaeyama Islands, located in the southwestern most part of the Ryukyu
Trench (Figure 1, region C) (Heki and Kataoka 2008), which showed the distinctive feature of biannually repeating $M_{w} \sim 6.6 \mathrm{SSE}$ events with durations of approximately 1 month. The second case involved southeastern Kyushu (Yarai and Ozawa 2013), where long-term SSEs repeated in the afterslip region following $M_{w} 6.7$ and 6.8 interplate earthquakes in 1996 (Figure 1, region B). Each of the SSEs released a moment equivalent to a $M_{w} 6.8$ event over a period of about a year. The limited number of reported SSEs can probably be attributed to the lack of systematic searches for such events throughout the Ryukyu Trench region, even though Nishimura et al. (2013) did perform such a search along the Nankai Trough using GNSS data.

Although the Philippine Sea Plate subducts beneath both the Ryukyu Trench and Nankai Trough, the subduction zones along both have several different seismo-tectonic aspects. For example, the rate of relative interplate motion along the Ryukyu Trench predicted by a global plate model (Sella et al. 2002) is 70 to $91 \mathrm{~mm} /$ year, which is faster than the approximately $60 \mathrm{~mm} /$ year rate predicted along the Nankai Trough. Additionally, active spreading within the overriding plate proceeds only in the back-arc (the Okinawa Trough) region of the Ryukyu Trench (Letouzey and Kimura 1986; Nishimura et al. 2004) and causes the long-term slip rate to increase at the subduction interface. Furthermore, while $M_{w} 8$ to 9 megathrust earthquakes are known to have occurred repeatedly with an 
interval of 100 to 200 years along the Nankai Trough (e.g., Ishibashi 2004), the history of such events along the Ryukyu Trench is poorly understood. Possible megathrust earthquakes in documented history include an $M_{w} \sim 8$ event northeast of Amami-oshima in 1911 (Goto 2013) and an $M_{w} 7.4$ to 8 event south of the Yaeyama Islands in 1771 (Nakamura 2006, 2009). While the latter caused devastating tsunamis that resulted in approximately 12,000 causalities in the Yaeyama Islands, the locations and focal mechanisms of these earthquakes continue to be debated. Studies of contemporary deformations observed by GNSS suggest a high degree of interplate locking along the Nankai Trough (Ito et al. 1999; Liu et al. 2010) in contrast to substantial creep along the Ryukyu Trench (Nishimura et al. 2004). These tectonic setting differences can probably be attributed to the frequency, size, and duration of slow earthquakes, including SSEs, in those areas.

In this study, we attempt to identify the occurrences of short-term SSEs along the Ryukyu Trench by using GNSS data to detect the small episodic displacements caused by such events, after which we estimate fault models for short-term SSEs along both the Ryukyu Trench and western part of the Nankai Trough. We then discuss the regional characteristics of the detected SSEs.

\section{Methods}

We used data obtained from the GNSS Earth Observation Network System (GEONET) operated by the Geospatial Information Authority of Japan (GSI) and daily coordinates from 3 October 1996 to 8 February 2014, under the so-called GSI F3 strategy for the GNSS baseline analysis (Nakagawa et al. 2009). The 352 continuous GNSS stations used in this study are indicated by the blue dots in southwestern Japan shown in Figure 1. The procedure used to detect short-term SSEs follows that of Nishimura et al. (2013) with some modifications. We first removed the coseismic offsets of 14 large earthquakes with magnitudes ranging from 6.4 to 9.0, which were estimated from the 10 days averages of daily coordinates observed before and after the earthquakes. While the epicenters of 11 of the abovementioned earthquakes are plotted in Figure 1, those of the other three earthquakes, which include the $M_{w} 9.0$ Tohoku-oki earthquake (e.g., Ozawa et al. 2011), are outside the figure area. The co-eruptive offsets of the Kirishima volcano from late January 2011 (e.g., Nakao et al. 2013) were also removed, along with anomalous noisy data that included large scatter and seasonal fluctuations for selected periods at some selected stations. Then, spatial filtering (Wdowinski et al. 1997) was applied to remove the common-mode bias for those stations. Because the spatial distribution of the stations used is as large as approximately $1,600 \mathrm{~km}$, we found significant commonmode bias in the GNSS time series after performing simultaneous spatial filtering for all stations. Therefore, the GNSS stations were divided into two groups, north and south of $\mathrm{N} 30^{\circ}$, after which spatial filtering was applied separately in each group in order to obtain noisereduced coordinates.

Next, we estimated day-by-day displacements of the north, east, and up components by fitting a linear function with an offset at the middle of a 180-day-long period. From the estimated offsets, we obtained threedimensional (3D) daily displacement values from 1 January 1997 to 10 November 2013. To identify the signal related to short-term SSEs, we focused on the $\mathrm{N} 45^{\circ} \mathrm{W}$ horizontal component, which is approximately parallel to the relative interplate motion along the Ryukyu Trench. Linear functions with and without an offset at the middle of a period were fitted to the $\mathrm{N} 45^{\circ} \mathrm{W}$ component. Then, we determined which function was a better fit according to Akaike's information criterion (AIC) (Akaike 1974). The difference between the AICs ( $\triangle \mathrm{AIC}$ ) of the two functions provides an index that can be used to indicate a significant displacement on a certain date. A zero $\triangle \mathrm{AIC}$ value was assigned when the time series had a positive offset because SSEs are expected to cause a negative offset, which is opposite to the interplate motion. If a short-term SSE causes a significant displacement, the displacement should be observed simultaneously at nearby GNSS stations. This allowed the calculation of an average $\triangle \mathrm{AIC}$ for the GNSS stations within a $160 \times 70 \mathrm{~km}$ rectangular area. The long sides of these rectangular areas were oriented in the $\mathrm{N} 45^{\circ} \mathrm{W}$ direction. Next, 141 points were selected at the center of the rectangular area in order to calculate these spatial average $\triangle \mathrm{AICs}$ (Figure 2A), after which the points were projected onto the $35 \mathrm{~km}$ isodepth of the subducting Philippine Sea Plate at $10 \mathrm{~km}$ intervals on a $\mathrm{N} 45^{\circ} \mathrm{E}$-oriented line roughly parallel to the Ryukyu Trench. Figure $2 \mathrm{~B}$ shows the average $\triangle \mathrm{AIC}$ with time and distance along the trench. The average $\triangle \mathrm{AIC}$ is only plotted at points corresponding to rectangular areas containing more than three GNSS stations. The vertical strips of low $\triangle$ AIC indicate that episodic displacement toward $\mathrm{N} 135^{\circ} \mathrm{E}$ is spatially coherent along the trench, which indicates a possible candidate of short-term SSEs. The stars represent local minima of $\triangle \mathrm{AIC}$. In total, 374 minima were selected in accordance with the following criteria: (1) $\triangle \mathrm{AIC}$ of less than -5 ; (2) the lowest $\triangle \mathrm{AIC}$ in a time range of \pm 12 days, and a distance range of $\pm 100 \mathrm{~km}$. After dozens of trials, it was possible to determine the parameters that could be used to visually identify the signals. The color of the stars represents event classification based on the fault model estimation result. The vertical stripes and stars coincide with clusters of active LFEs in Shikoku and the Bungo Channel, which supports the hypothesis that 


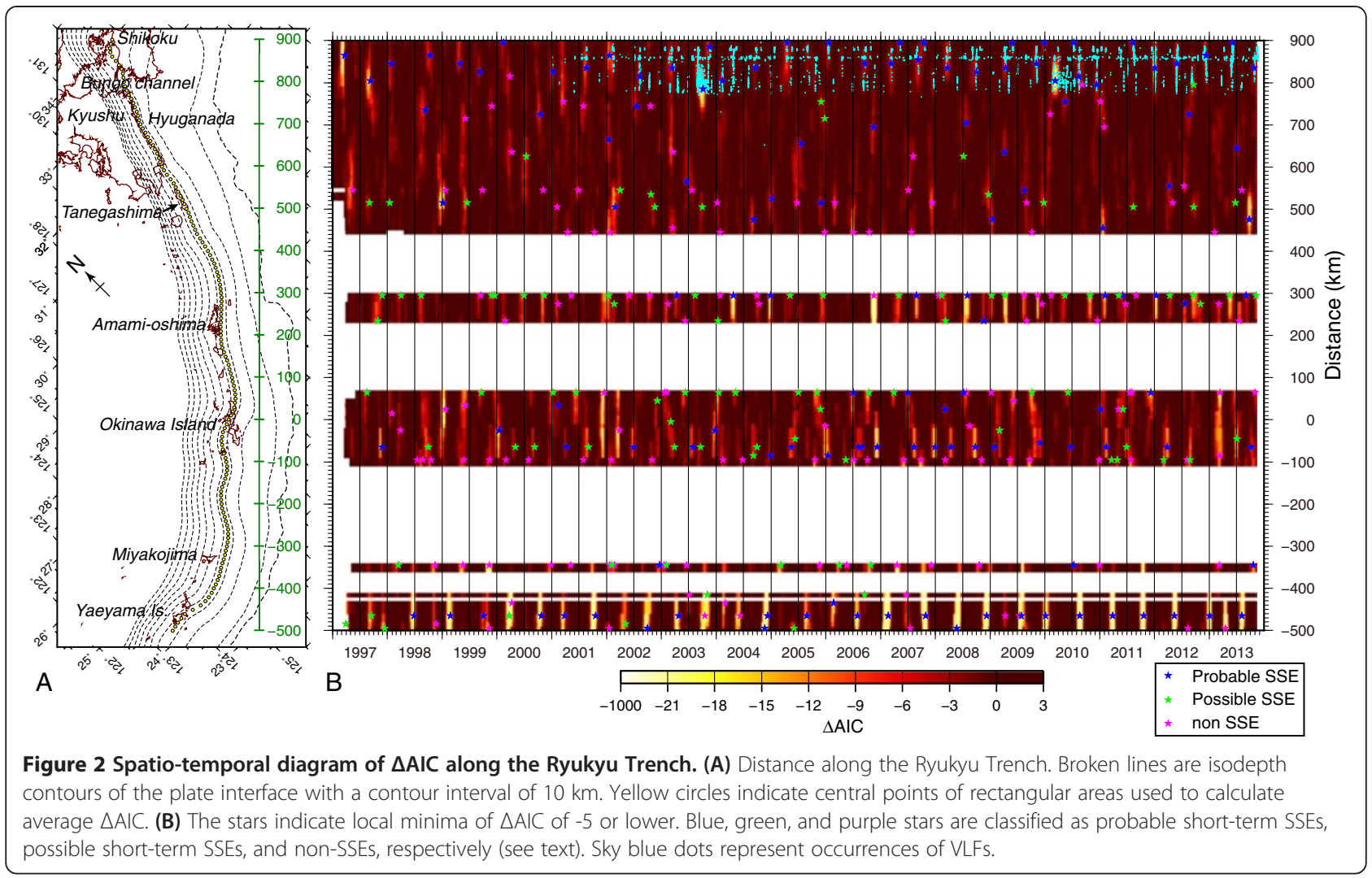

the detected deformation is related to short-term SSEs (Nishimura et al. 2013).

After episodic displacement detection, a fault model for a short-term SSE was estimated from the 3D displacement. The GNSS stations selected for use in the fault model inversion were within a radius of $200 \mathrm{~km}$ from the points used for the average $\triangle \mathrm{AIC}$. We began by assuming a rectangular fault model in an elastic halfspace (Okada 1985) and then applied the nonlinear inversion method formulated in Matsu'ura and Hasegawa (1987). Six rectangular fault parameters (i.e., longitude, latitude, length, width, rake, and slip amount) were the free parameters estimated in the inversion. A further three parameters (depth, strike, and dip) were assumed to depend solely on the horizontal location of the fault so that the rectangular fault would locate approximately on the subduction interface (Baba et al. 2002; Nakajima and Hasegawa 2007; Hirose et al. 2008; Hayes et al. 2012) (Figure 2A). We simultaneously estimated translation parameters for the north, east, and vertical components in the displacement data. The initial longitude and latitude parameters were those for the local $\triangle \mathrm{AIC}$ minima point. The inversion results depend on initial parameter values because the inversion method uses a linearized iteration to solve a nonlinear problem. Additionally, in the method proposed by Matsu'ura and Hasegawa (1987), the parameters are constrained to be initial values as a priori information. The initial values for fault location at a depth of $35 \mathrm{~km}$ on the subducting plate are reasonable in the case of the Nankai Trough (Nishimura et al. 2013) because SSEs occur in a narrow LFT band at this depth. However, they are difficult to justify along the Ryukyu Trench because SSE locations are poorly understood there. Therefore, to reduce our dependency on the abovementioned initial values, we added an additional six sets of initial values for fault locations. The initial locations in the additional sets surround the original point for the local minima of $\triangle \mathrm{AIC}$ at a radius of $70 \mathrm{~km}$, located $60^{\circ}$ apart. The other initial values used were $40 \mathrm{~km}, 35 \mathrm{~km}, 90^{\circ}$, and $10 \mathrm{~mm}$ for length, width, rake, and slip, respectively.

Two criteria were used to classify each SSE model as a probable SSE, possible SSE, or non-SSE. The first criterion is the azimuth of the estimated slip vector. Because SSE slip vectors are expected to be approximately opposite to the relative plate motion, we chose events whose slip directions ranged between $\mathrm{N} 90^{\circ} \mathrm{E}$ and $\mathrm{N} 180^{\circ}$ E. Other events were classified as non-SSE. The second criterion is how well the fault model explained the data. We calculated chi-square values representing nonconformist data for the fault model inversion and an inversion in order to estimate only translation parameters. The chi-square reduction was calculated by subtracting the chi-square for the fault model inversion from that 
for the translation parameter inversion. Finally, we compared the fault models estimated from seven initial values and chose the preferred model according to the largest chi-square reduction under the slip direction criterion. We then categorized events with chi-square reductions exceeding 30 and 100 into possible and probable SSEs, respectively. Figure 3 shows examples of estimated fault models that were classified as probable SSEs. When calculating SSE moment magnitudes, we assumed a rigidity of $40 \mathrm{GPa}$.

However, it should be noted that even if the estimated fault models meet the criteria for probable or possible SSEs, false and missed SSE detections are unavoidable in this study because the detected displacement was approximately $2 \mathrm{~mm}$ and comparable, in most cases, to the noise level. Accordingly, we manually excluded some areas and events in order to make a reliable catalogue of short-term SSEs. For example, because the two hatched regions in Figure 4 are located far from the GNSS stations, even the $M_{w} \sim 7 \mathrm{SSEs}$ in these regions may cause a very small $(\leq 1 \mathrm{~mm})$ displacement at the nearest station, which makes it difficult to determine whether the SSEs in these regions are real phenomena. Therefore, we excluded the SSEs identified in these regions. We also found several cases in which SSE models on the plate interface apparently fit coseismic displacement of intraplate earthquakes, including shallow crustal and normalfaulting earthquakes, and residual displacement after a correction of coseismic displacement for the 14 large earthquakes. In the end, we had manually excluded 21 probable and possible SSEs.

\section{Results}

In total, 130 probable and 93 possible short-term SSEs were identified from the period from 1 January 1997 to 10 November 2013. The parameters of each SSE are described in Additional file 1 of the online supplement. Figure 4 shows the fault models, cumulative slip, and the cumulative number of occurrences for all probable and possible SSEs along the Ryukyu Trench over the approximately 17 -year period.

We identified several clusters of short-term SSEs, which we named clusters C1 to C6 (Figure 4). The estimated moment magnitude for all identified SSEs ranges from 5.6 to 6.8 (Figure 5). These figures suggest that large short-term SSEs occur frequently along the Ryukyu Trench, which is in contrast with the Nankai Trough along which the largest event is $M_{w} 6.3$ (Sekine et al. 2010; Nishimura et al. 2013). The largest SSE detected in this study is an event that occurred south of the Yaeyama Islands on 19 November 2004. However, there are large amounts of uncertainty in the estimated parameters of this event because it is located at the margin of the GNSS network we used. It is also notable that the uncertainties in the parameters for SSEs along the Ryukyu Trench are larger than those along the Nankai Trough because the GNSS network is less dense along the Ryukyu Trench and the SSEs here occur offshore, away from the GNSS stations. Figure 6 shows the spatio-temporal distribution of short-term SSEs along the trench. Each SSE is represented by a green or light-green rectangle with a vertical blue bar indicating the date of occurrence. The more extensive the space is filled by the green and light-green rectangles, the greater the interplate slip that was accommodated by the short-term SSEs (see Figure 6). We will discuss the characteristics of the detected short-term SSEs using these figures in the following sections.

\section{Discussion}

\section{Examples of individual short-term SSEs}

Here, we provide an overview of some of the individual events shown in Figure 3. In western Shikoku and the Bungo Channel, the available LFE data indicates that shortterm SSE always accompanies LFEs. Figure 3A shows an example of this ETS-type SSE. However, there are various relationships between the short-term SSEs and seismic activities, such as regular earthquakes, LFTs, LFEs, and VLFEs in the other regions. Short-term SSEs along the Ryukyu Trench, even those just southwest of the Bungo Channel, do not accompany LFEs, as shown Figure 3B,C. However, we recognized that some SSEs coincide with regular earthquakes. One example is the $M_{w}$ 6.4 SSE detected just beneath Okinoerabujima north of Okinawa Island on 6 July 2008 (Figure 3F). Since the F-net centroid moment tensor (CMT) catalogue (Fukuyama et al. 1998) shows that an $M_{w} 6.0$ interplate earthquake, whose epicenter is plotted in Figure 3F, occurred on 8 July 2008, this event may be regarded as a coseismic and post-seismic slip rather than a short-term SSE. However, we classified this event as a probable SSE because the moment estimated in this study was approximately six times as large as the seismic moment of the CMT solution. The detected SSE occurred 2 days before the $M_{w} 6.0$ earthquake, which is an insignificant time difference within the temporal uncertainty of the method used, i.e., less than a week (Nishimura et al. 2013). An SSE that occurred on 24 September 2013 (Figure 3D) coincides with a seismic swarm including a maximum $M_{w} 5.1$ earthquake southeast of Tanegashima. The seismic swarm continued from early September to mid-October 2013. The estimated SSE moment is larger than that of the cumulative seismic activity moment by an order of magnitude. The seismic activity was probably triggered by the SSE, as in the case of the SSEs in the Boso Peninsula (Ozawa et al. 2007; Hirose et al. 2012).

\section{Characteristics of short-term SSE clusters}

In this section, we discuss several individual clusters. A distinctive cluster of short-term SSEs (C4) is located 

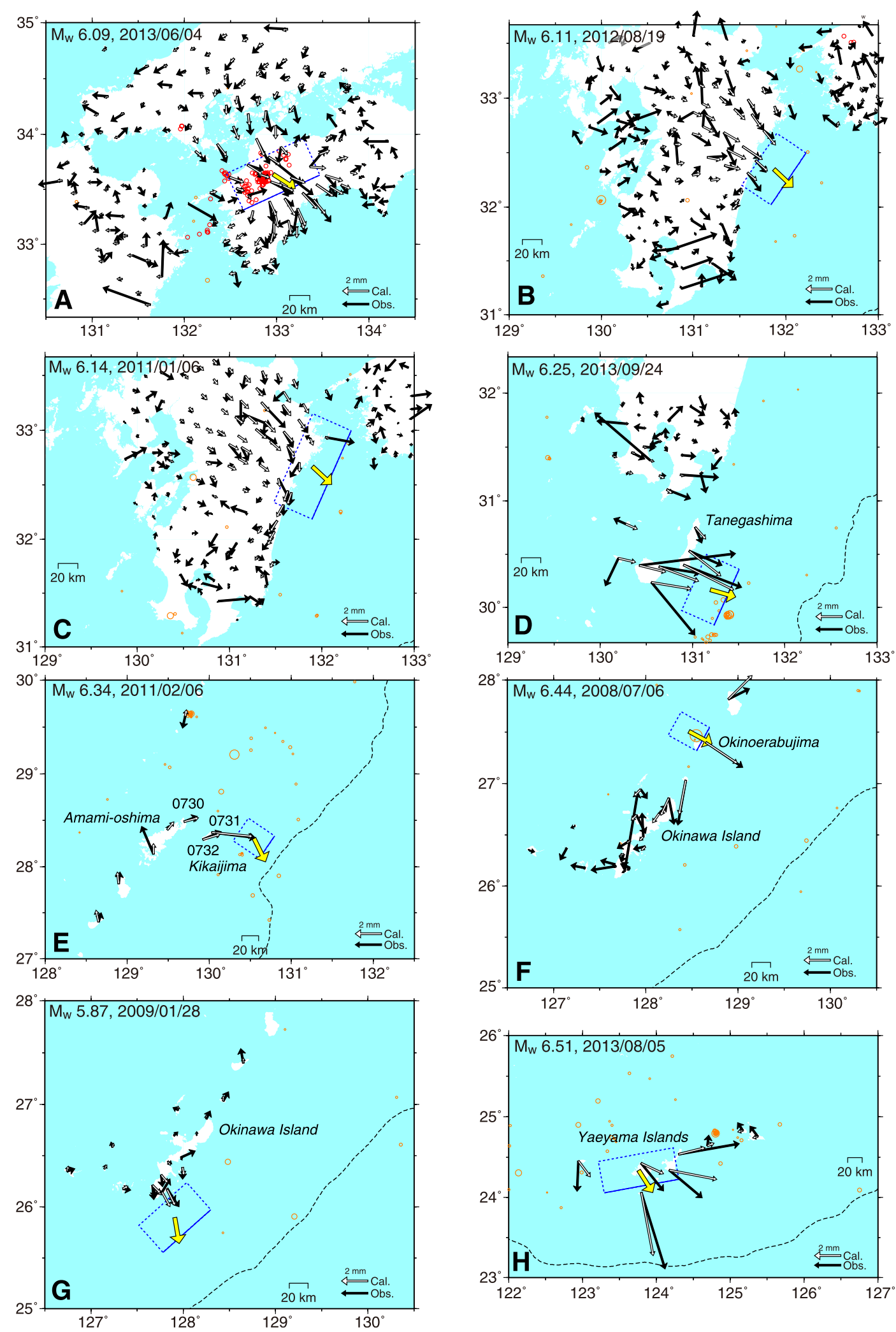

Figure 3 (See legend on next page.) 
(See figure on previous page.)

Figure 3 Examples of estimated fault models for probable short-term SSEs. Black and white vectors indicate observed and calculated horizontal displacement, respectively. Yellow vectors represent estimated slip vectors. Blue broken rectangles indicate the estimated rectangular faults. Blue solid lines represent their upper edges. Orange and red circles indicate epicenters of regular and low-frequency earthquakes for the 5 days centering on the day indicated, respectively. (A) SSE in western Shikoku (B) SSE in mid Kyushu (C) SSE in mid-Kyushu (D) SSE southeast off Tanegashima (E) SSE east off Kikaijima (F) SSE in Okinoerabujima (G) SSE southeast off southern Okinawa Island (H) SSE in the Yaeyama Islands.

northeast of Kikaijima in a very shallow (approximately $10 \mathrm{~km}$ ) region near the trench. The cluster consists of 15 short-term SSEs in the 6.0 to $6.3 M_{w}$ range. An example of the SSEs belonging to this cluster is shown in Figure 3E. The displacement at GNSS station 0731 in the eastern part of Kikaijima is eastward by approximately $3 \mathrm{~mm}$ and is much larger than those at other stations. The total slip for the approximately 17 years is $0.7 \mathrm{~m}$, which is the second highest peak along the studied area. The intense short-term SSE activity seen in a very shallow region may be related to the topography of the subducting plate. The Amami Plateau is subducting near Kikaijima (Figures 1B and 4), and the location of cluster $\mathrm{C} 4$ coincides with that of subducted seamounts, which are a part of the Amami Plateau (Nakazawa et al. 2008). Wang and Bilek (2011, 2014) proposed that the subducted seamounts cause creep, including SSEs, on the plate interface, which is concordant with our results.

Next, we examined signals related to the short-term SSEs in daily coordinates of the GNSS stations on Kikaijima and Amami-oshima (Figure 7). We found that the downward offsets related to cluster C4 SSEs are clear in the daily coordinates at station 0731 and become smaller at stations 0732 and 0730 . The daily coordinates, as well as the temporal distribution of the SSEs (Figure 6), indicate that the recurrence interval of the SSEs is irregular, varying from several months to a few years. We speculate that the irregular interval of the SSEs is not solely attributable to the limited detectability of SSEs, but is also due to the large diversity in the duration and magnitude of SSEs in the surrounding region. For example, the downward movement associated with SSEs is usually complete within a week, but the movement in August 2008 continued for more than 2 months (Figure 7). Furthermore, the slant between each short-term SSE is not constant and changes even during the inter-SSE period, which is clearly seen in the periods of May 2010 to October 2010, and June 2011 to January 2012. These observations suggest that various SSEs, with durations of days to years, occur in the region near Kikaijima.

The SSEs of cluster C6 in the Yaeyama Islands correspond to the biannually repeating SSEs studied by Heki and Kataoka (2008). Our results also show that the SSEs continued to occur approximately every half year (Figure 6), even though three events in late 2003, mid-2004, and early 2007 were missed in this study. More specifically, this study detected episodic deformation related to two of these three events in the GNSS time series (Figure 2) but failed to estimate a reasonable fault model. The peak for cluster C6 SSEs in the magnitude histogram is $M_{w} 6.45$ (Figure 5), which is the largest for all the clusters. From a total of 34 events with $M_{w} \geq 6.4,19$ were cluster C6 SSEs. Cluster C6 in the Yaeyama Islands, therefore, consists of the largest short-term SSEs in southwestern Japan. A significant difference between our result and a previous study (Heki and Kataoka 2008) occurs in the estimated moment magnitude. The average medium magnitude estimated in that study was 6.6 , which is larger than our estimate by $M_{w} 0.2$. This difference is probably due to the fact that our detection method ignores SSE durations, which are a month on average. Fitting a linear function with a spontaneous offset to slow transient deformation causes the episodic displacement to be underestimated. Additionally, numerical experiments using synthetic time series suggest that our method underestimates transient displacement with duration of 20 days by $20 \%$ at maximum. The moment magnitude of this study, therefore, must be underestimated, and a similar underestimation probably occurred for other SSEs with durations of more than 2 weeks in the present study.

In contrast with cluster C6, cluster C5 consists of 29 $M_{w} \leq 6.0$ SSEs (Figure 5F). This cluster is located southeast of southern Okinawa Island and includes the most frequently repeating SSEs along the Ryukyu Trench (Figures 4C and 6). An example of the SSEs in this cluster is shown in Figure 3G. Although the total number of cluster C5 SSEs is large, the cumulative slip for the approximately 17-year period is only $0.3 \mathrm{~m}$ at maximum, which is approximately $20 \%$ of the rigid interplate motion. Among the cluster C5 SSEs, we can recognize similarities in terms of magnitude, recurrence interval, and slip ratio between the short-term SSEs and the rigid plate motion, and the short-term SSEs in the ETS zone along the Nankai Trough. Although LFTs have never been detected along the Ryukyu Trench, VLFEs (e.g., Ito et al. 2009) have recently been discovered in the region (Ando et al. 2012; Asano et al. 2013). A preliminary study has suggested coincidental occurrences of short-term SSEs and VLFEs southeast off Okinawa Island (Y. Asano, personal communication, 2013), but further study will be required to clarify the relationship among slow earthquakes in other regions.

Cluster C3 near Tanegashima consists of short-term 5.9 to $6.3 M_{w}$ SSEs. Whereas clusters C4 to C6 consist of repeating SSEs whose source areas mostly overlap, the 


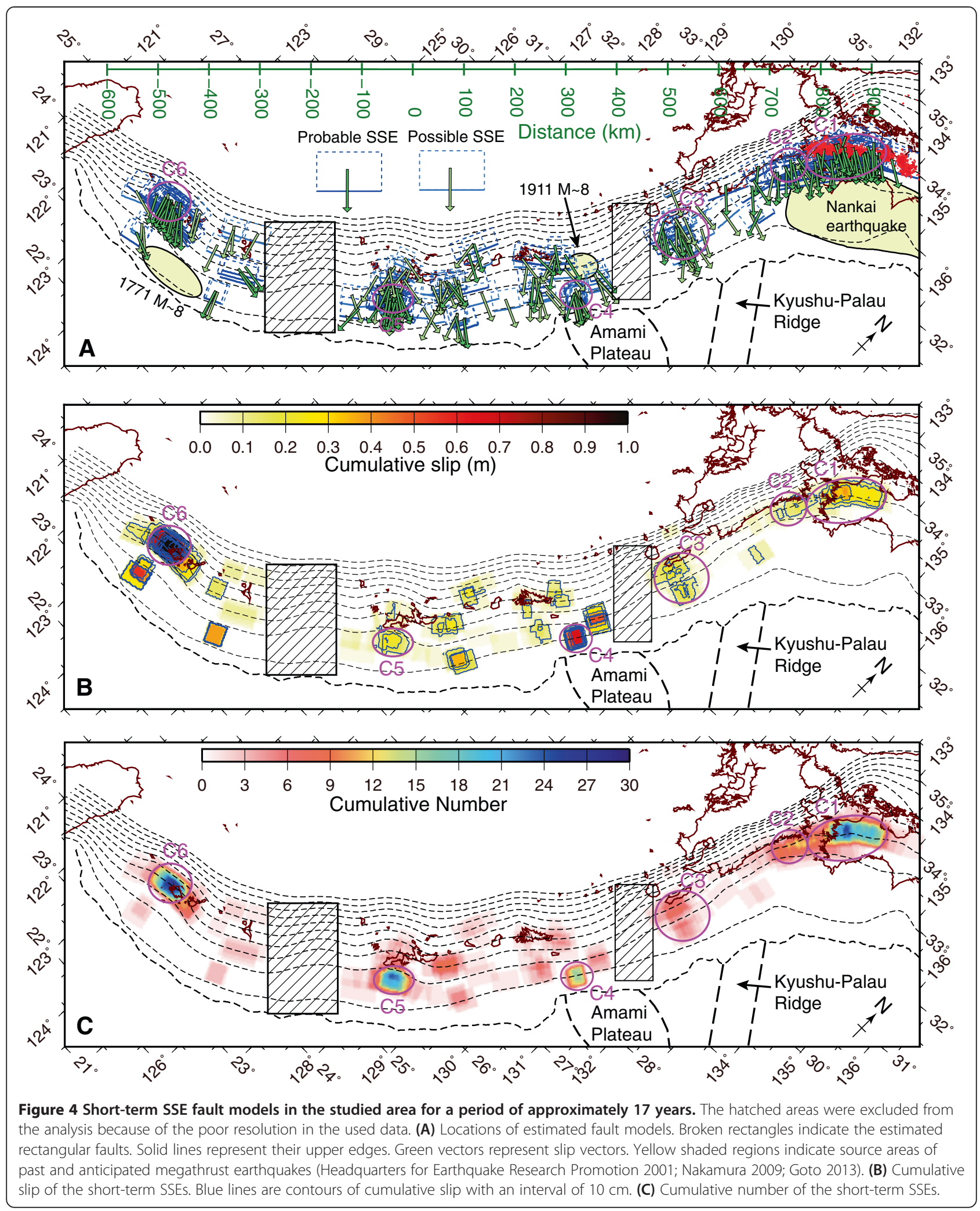



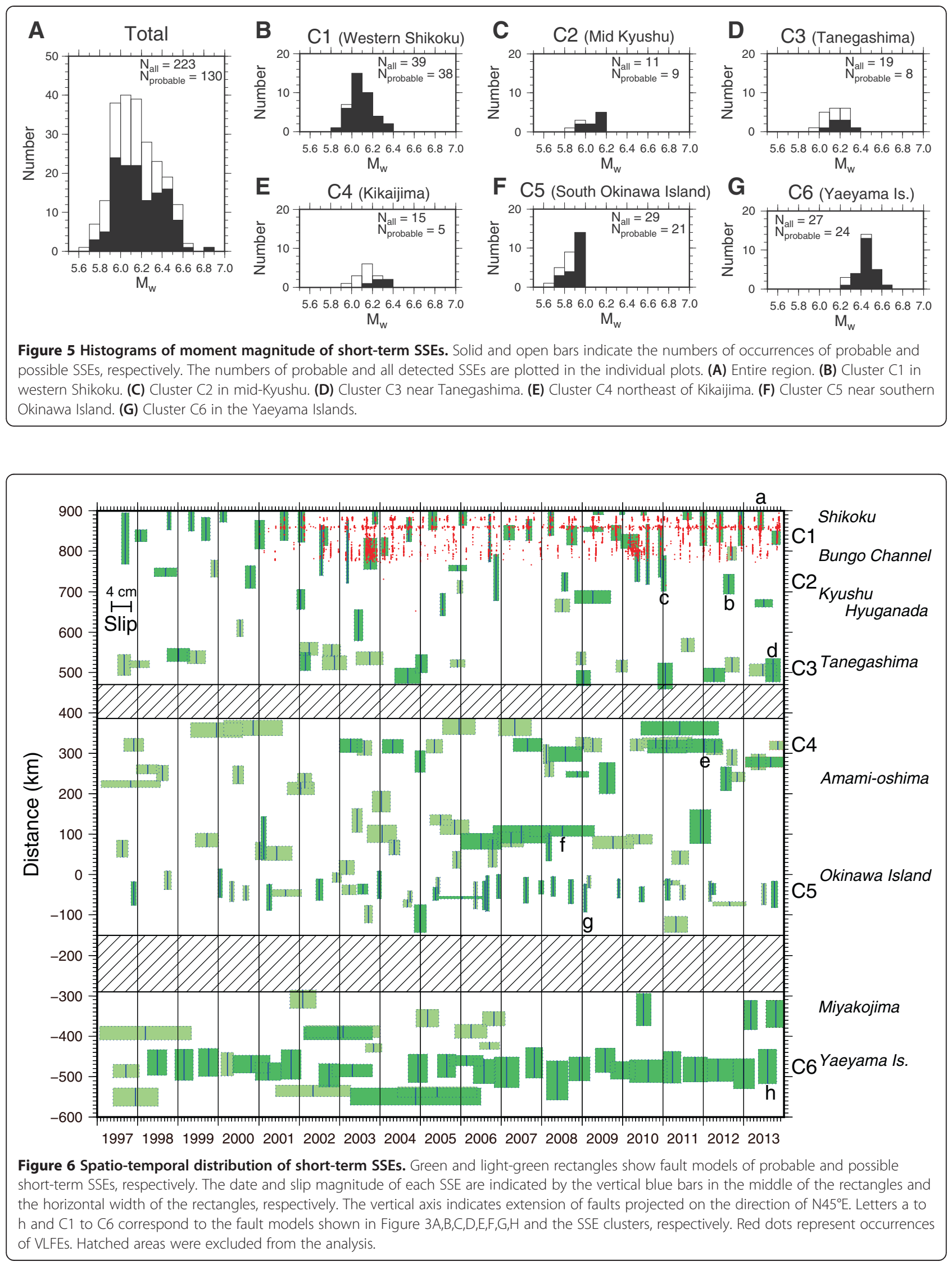


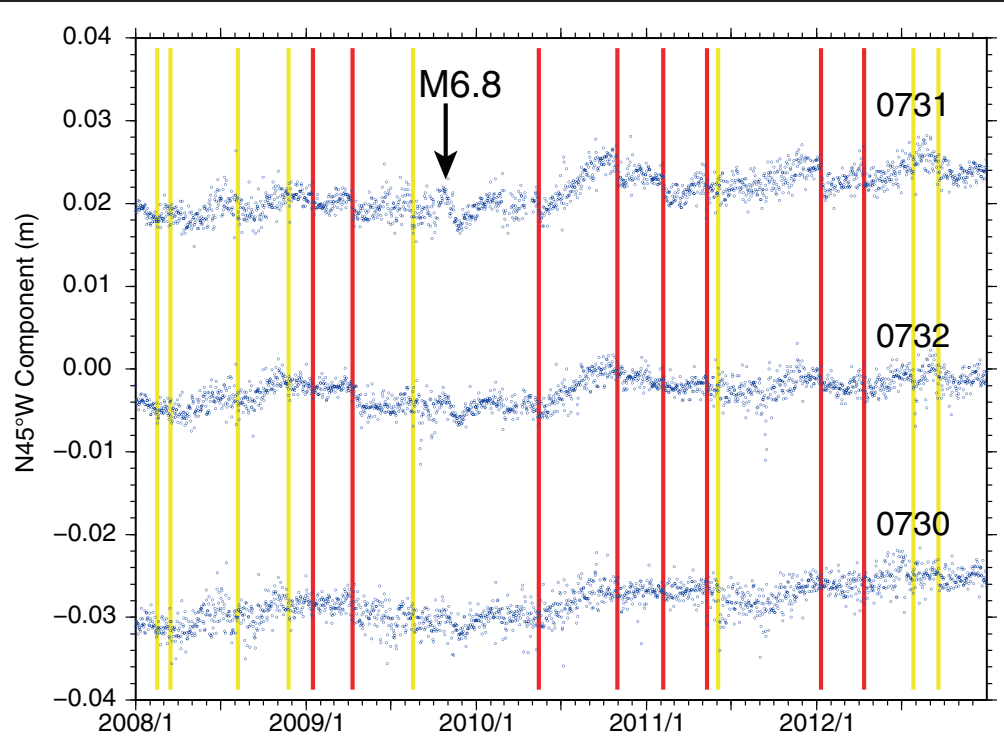

Figure 7 De-trended time series of selected GNSS stations in Kikaijima and Amami-oshima from 2008 to 2012 . The horizontal N45 W component was plotted after removal of a linear trend for 1997 to 2013. Red and yellow vertical lines indicate the occurrence of cluster C4 SSES and other nearby SSES, respectively. Four-digit numbers represent GNSS station IDs. Their locations are shown in Figure 3F. An arrow indicates the occurrence of the $M_{w} 6.8$ interplate earthquake whose epicenter is $120 \mathrm{~km}$ north of Kikaijima. The coseismic displacement of the earthquake is corrected.

slip areas of cluster C3 SSEs are somewhat scattered. The short-term SSEs of cluster C3 tend to accompany nearby regular earthquake activities, as in the example discussed in the previous section (Figure 3D).

\section{Spatial distribution of short-term SSEs}

The overall distribution of SSEs (Figure 4) suggests that short-term SSEs are common phenomena throughout the area from Shikoku to the Yaeyama Islands. It also indicates a degree of spatial heterogeneity, that is, shortterm SSEs frequently occur in some areas but not in others. Although the observed heterogeneous SSE distribution is partly artificial due to inhomogeneous levels of detectability resulting from the GNSS network used, it must also reflect the true distribution of short-term SSEs. The total slip and number of SSEs vary along the east coast of Kyushu and the southeastern coast of Okinawa Island (Figure 4), even under a similar station distribution (Figure 1), which suggests that the true distribution of SSEs is not spatially equal. Most short-term SSEs occur at a depth of $\leq 50 \mathrm{~km}$, but some exceptionally deep events occur along the Ryukyu Trench.

One interesting feature is that a band of short-term SSEs in western Shikoku (cluster C1) extends to Kyushu through the Bungo Channel (cluster C2) in the same depth range (30 to $45 \mathrm{~km}$ ), even though few LFEs or LFTs occur southwest of the Bungo Channel (Yoshioka et al. 2008; Yabe and Ide 2013). The total slip magnitude and total number of SSEs gradually decrease toward the south and diminish in southeastern Kyushu. Additionally, while short-term SSEs on the band become less frequent toward the south, several SSEs have been identified offshore beyond the band at a depth of $\leq 20 \mathrm{~km}$. It is notable that this transition zone corresponds to the source area of the long-term SSEs (Figure 1, region B) (Yarai and Ozawa 2013), two 1996 earthquakes, and their afterslip (Yagi et al. 2001). The locking state of the interface estimated from the average GNSS velocity from 1996 to 2005 (Wallace et al. 2009) also shows a transition from full locking off Shikoku to significant creep off Kyushu. Park et al. (2009) proposed that the subducted KyushuPalau Ridge controls the seismic slip behavior in this region. Considering the Kyushu-Palau Ridge and Amami Plateau along with the distribution of short-term SSEs, our study supports the hypothesis that the subducted plate topography controls the behavior of seismic and aseismic slip on the plate interface (e.g., Mochizuki et al. 2008; Wang and Bilek 2011, 2014).

The spatio-temporal distribution of the short-term SSEs (Figure 6) shows that several individual SSEs stretching from Shikoku to Kyushu caused LFEs in the Bungo Channel, but not in Kyushu. These events occurred frequently in 2003 and 2010, when long-term SSEs occurred in the Bungo Channel (Ozawa et al. 2013). The occurrence of short-term SSEs without LFEs and LFTs may not be surprising, because several such events have been observed previously, including those beneath the Boso Peninsula in central Japan (Ozawa et al. 2007) and in the Hikurangi subduction zone of New Zealand (Wallace et al. 2012). Even in tremor-genic ETS zones like the Nankai Trough and the Cascadia subduction zone, recent observations have detected some SSEs without LFEs and VLFs (Obara 
and Sekine 2009; Nishimura et al. 2013; Wech and Bartlow 2014). Since the depth ranges provide similar temperature and pressure conditions, within or outside the SSE fault zone, the important question is 'What causes the difference between SSEs with LFEs and LFTs and those without in the same depth range?' One possible answer is that the dip of the plate interface causes some stress state differences in the fault zone, because the plate interface in the SSE-genesis zone dips gently by approximately $10^{\circ}$ in Shikoku and steeply by approximately $30^{\circ}$ in Kyushu. Additionally, while Wech and Bartlow (2014) suggested the hypothesis that the slip rate controls the occurrence of LFTs, this study is not capable of validating their hypothesis because SSE slip rate could not be estimated due to the limited temporal resolution in the low signal-to-noise ratio dataset. However, future studies on the temporal evolution of each SSE using tilt data with high temporal resolution (e.g., Hirose and Obara 2010) could provide clues clarifying the relation between SSEs and other slow earthquakes, including LFTs, LFEs, and VLFEs.

Another interesting feature of the general SSE distribution is that many shallow SSEs with depths of $\leq 20 \mathrm{~km}$ were detected along the Ryukyu Trench, but no shallow SSEs were detected along the Nankai Trough south of Shikoku. The region in which no short-term SSEs were detected roughly coincides with that of the nearly full locking region estimated from the average GNSS velocity over a decade (Wallace et al. 2009; Liu et al. 2010). That region has also been regarded as the source area of the repeated $M_{w} \geq 8$ Nankai earthquakes (Headquarters for Earthquake Research Promotion 2001; Ishibashi 2004). The absence of short-term SSEs suggests that the region, except for the source area of the long-term SSEs (Figure 1, region A), steadily accumulates strain for future megathrust earthquakes along the Nankai Trough, although we cannot rule out significant creep and SSEs near the trough axis, which is a region that cannot be clarified by on-land GNSS data. In contrast, no space free from short-term SSEs with a spatial extent of more than $200 \mathrm{~km}$ exists along the Ryukyu Trench, except for the areas that we excluded in the analysis. Additionally, studies on average GNSS velocity show no evidence of interplate locking along the Ryukyu Trench (Nakamura 2004; Nishimura et al. 2004). These results suggest that aseismic slip accommodates most of the interplate motion and that the potential for a giant $\left(M_{w} \geq 8.5\right)$ megathrust earthquake is low. Although the abundant SSEs detected in this study contribute to aseismic slip, the cumulative slip of the short-term SSEs is small and represents just a small part of the interplate slip (1.2 to $1.7 \mathrm{~m}$ ) predicted from the global plate model (Sella et al. 2002) for the approximately 17-year period, except for clusters $\mathrm{C} 4$ and $\mathrm{C} 6$, whose total slips are approximately 1.4 and $0.7 \mathrm{~m}$, respectively (Figure 4B).
These observations suggest that steady creep and/or undetected long-term SSEs play an important role in accommodating the interplate motion along the Ryukyu Trench. Additionally, the source areas of the $M_{w} \sim 8$ earthquakes that occurred in 1771 and 1911 do not overlap the distribution of the short-term SSEs. Even if these source areas are locked, it would be difficult to detect an offshore locked area of these sizes due to the sparsity of the GNSS network along the Ryukyu Trench. Accordingly, this study cannot rule out the potential for $M_{w} \sim 8$ earthquakes like the ones that occurred in 1771 and 1911 along the Ryukyu Trench.

\section{Conclusions}

This study clarified the spatial-temporal distribution of short-term SSEs on the interface of the subducting Philippine Sea Plate along the Ryukyu Trench from western Shikoku to the Yaeyama Islands of southwestern Japan. We then applied the short-term SSE detection method of Nishimura et al. (2013), with some modifications, using continuous GNSS data. Rectangular fault models for 130 probable and 93 possible SSEs were estimated on the plate interface from January 1997 to November 2013. The moment magnitude of the estimated fault models ranged from 5.6 to 6.8, although the value in this study may be underestimated for SSEs with durations of 2 weeks and longer.

We found that the estimated short-term SSEs are distributed heterogeneously. If we assume that the SSEs occur on the plate interface, most are in the depth range of 10 to $60 \mathrm{~km}$. Shallow SSEs with a depth of $\leq 20 \mathrm{~km}$, which have been never detected along the Nankai Trough, are common along the Ryukyu Trench. Although short-term SSEs accompanied by LFEs and LFTs are concentrated in an ETS band along the Nankai Trough, SSEs without LFEs and LFTs form several clusters along the Ryukyu Trench. The SSE band extends from west Shikoku to mid-Kyushu across the Bungo Channel, whereas the LFEs and LFTs disappear at Kyushu. The SSE band diminishes in southeastern Kyushu, where the Kyushu-Palau Ridge subducts. We also found distinct SSE clusters southeast of southern Okinawa Island and northeast of Kikaijima. The former cluster consists of rather small SSEs with $M_{w} \leq 6.0$ at a depth of approximately $20 \mathrm{~km}$, and the latter cluster consists of very shallow SSEs with $M_{w}$ of 5.9 to 6.3 at depths of approximately $10 \mathrm{~km}$. The location of the latter cluster corresponds to subducted seamounts that are a part of the Amami Plateau. Our results suggest that the rough topography of the subducting plate may favor short-term SSEs on the shallow plate interface at a depth of $\leq 20 \mathrm{~km}$.

\section{Additional file}

Additional file 1: Parameters of each SSE. 


\section{Abbreviations}

ETS: Episodic tremor and slip; GEONET: GNSS Earth Observation Network System; GNSS: Global navigation satellite system; LFE: Low-frequency earthquake; LFT: Low-frequency tremor; $M_{w}$ : Moment magnitude; SSE: Slow slip event; VLFE: Very low frequency earthquake.

\section{Competing interests}

The author declares that he has no competing interests.

\section{Acknowledgements}

The author would like to thank the Geospatial Information Authority of Japan, the Japan Meteorological Agency, and the National Research Institute of Earth Science and Disaster Prevention for providing the GEONET, seismicity, and focal mechanism data, respectively. The author also extends thanks two the anonymous reviewers and Editor Teruyuki Kato for their thoughtful comments. Finally, the author would like to express his gratitude to Drs. Hitoshi Hirose, Kazushige Obara, and Ryoko Nakata who are conveners of the Japan Geoscience Union session on 'Slow earthquakes' for encouraging him to submit the paper to PEPS. This study was supported by the Tokyo Marine Kagami Memorial Foundation and the new disaster research project on megathrust earthquakes and Nankai/Ryukyu subduction zones.

\section{Received: 18 April 2014 Accepted: 21 September 2014}

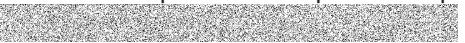

\section{References}

Akaike H (1974) A new look at the statistical model identification. IEEE Trans Auto Control 19:716-723, doi:10.1109/TAC.1974.1100705

Ando M, Tu Y, Kumagai H, Yamanaka Y, Lin CH (2012) Very low frequency earthquakes along the Ryukyu subduction zone. Geophys Res Lett 39:L04303, doi:10.1029/2011GL050559

Asano Y, Matsuzawa T, Obara K (2013) Detection and location of very low frequency earthquakes along the Ryukyu subduction zone (in Japanese). Abstract presented at the 2013 fall meeting, the Seismological Society of Japan, Yokohama, October 7-9, 2013

Baba T, Tanioka Y, Cummins PR, Uhira K (2002) The slip distribution of the 1946 Nankai earthquake estimated from tsunami inversion using a new plate model. Phys Earth Planet Inter 132:59-73, doi:10.1016/S0031-9201(02)00044-4

Beroza GC, Ide S (2011) Slow earthquakes and nonvolcanic tremor. Annu Rev Earth Planet Sci 39:271-296, doi:10.1146/annurev-earth-040809-152531

Fukuyama E, Ishida S, Dreger DS, Kawai H (1998) Automated seismic moment tensor determination by using on-line broadband seismic waveforms (in Japanese with English abstract). J Seismol Soc Jpn 2(51):149-156

Goto K (2013) Re-evaluation of hypocenter of the 1911 great earthquake around Kikai-jima, Japan (in Japanese with English abstract). J Seismol Soc Jpn 2 (65):231-242, doi:10.4294/zisin.65.231

Hayes GP, Wald DJ, Johnson RL (2012) Slab1.0: a new three-dimensional model of global subduction interface geometry. J Geophys Res 117:B01302

Headquarters for Earthquake Research Promotion (2001) Long-term evaluation of the Nankai trough earthquakes (in Japanese). http://www.jishin.go.jp/main/ chousa/01sep_nankai/index.htm. Accessed 10 Apr 2014

Heki K, Kataoka T (2008) On the biannually repeating slow-slip events at the Ryukyu Trench, southwestern Japan. J Geophys Res 113:B11402, doi:10.1029/ 2008JB005739

Hirose H, Obara K (2010) Recurrence behavior of short-term slow slip and correlated nonvolcanic tremor episodes in western Shikoku, southwest Japan. J Geophys Res 115:B00A21, doi:10.1029/2008JB006050

Hirose H, Hirahara K, Kimata F, Fujii N, Miyazaki S (1999) A slow thrust slip event following the two 1996 Hyuganada earthquakes beneath the Bungo Channel, southwest Japan. Geophys Res Lett 26:3237-3240

Hirose F, Nakajima J, Hasegawa A (2008) Three-dimensional seismic velocity structure and configuration of the Philippine Sea slab in southwestern Japan estimated by double-difference tomography. J Geophys Res 113:B09315, doi:10.1029/2007JB005274

Hirose H, Kimura H, Enescu B, Aoi S (2012) Recurrent slow slip event likely hastened by the 2011 Tohoku earthquake. Proc Natl Acad Sci U S A 109 (38):15157-15161, doi:10.1073/pnas.1202709109

Ishibashi K (2004) Status of historical seismology in Japan. Ann Geophys 47:339-368

Ito T, Yoshioka S, Miyazaki S (1999) Interplate coupling in southwest Japan deduced from inversion analysis of GPS data. Phys Earth Planet Inter 115:17-34
Ito Y, Asano Y, Obara K (2009) Very-low-frequency earthquakes indicate a transpressional stress regime in the Nankai accretionary prism. Geophys Res Lett 36:L20309, doi:10.1029/2009GL039332

Kobayashi A (2010) A small-scale long-term slow slip that occurred in western Shikoku in 2005 (in Japanese). J Seismol Soc Jpn 2(63):97-100, doi:10.4294/ zisin.63.97

Letouzey J, Kimura M (1986) The Okinawa Trough: genesis of a back-arc basin developing along a continental margin. Tectonophys 125:209-230, doi:10.1016/0040-1951(86)90015-6

Liu Z, Owen S, Dong D, Lundgren P, Webb F, Hetland E, Simons M (2010) Estimation of interplate coupling in the Nankai trough, Japan using GPS data from 1996 to 2006. Geophys J Int 181:1313-1328, doi:10.1111/j.1365246X.2010.04600.X

Matsu'ura M, Hasegawa Y (1987) A maximum likelihood approach to nonlinear inversion under constraints. Phys Earth Planet Inter 47:179-187, doi:10.1016/ 0031-9201(87)90076-8

Mochizuki K, Yamada T, Shinohara M, Yamanaka Y, Kanazawa T (2008) Weak interplate coupling by seamounts and repeating $M 7$ earthquakes. Science 321:1194-1197, doi:10.1126/science.1160250

Nakagawa H, Toyofuku T, Kotani K, Miyahara B, Iwashita C, Kawamoto S, Hatanaka Y, Munekane H, Ishimoto M, Yutsudo T, Ishikura N, Sugawara Y (2009) Development and validation of GEONET new analysis strategy (version 4) (in Japanese). J Geograph Surv Inst 118:1-8

Nakajima J, Hasegawa A (2007) Subduction of the Philippine Sea plate beneath southwestern Japan: slab geometry and its relationship to arc magmatism. J Geophys Res 112:B08306, doi:10.1029/2006JB004770

Nakamura M (2004) Crustal deformation in the central and southern Ryukyu Arc estimated from GPS data. Earth Planet Sci Lett 217:389-398, doi:10.1016/ S0012-821X(03)00604-6

Nakamura M (2006) Source fault model of the 1771 Yaeyama tsunami, southern Ryukyu Islands, Japan, inferred from numerical simulation. Pure Appl Geophys 163:41-54, doi:10.1007/s00024-005-0007-9

Nakamura M (2009) Fault model of the 1771 Yaeyama earthquake along the Ryukyu Trench estimated from the devastating tsunami. Geophys Res Lett 36:L19307, doi:10.1029/2009GL039730

Nakao S, Morita Y, Yakiwara H, Oikawa J, Ueda H, Takahashi H, Ohta Y, Matsushima T, Iguchi M (2013) Volume change of the magma reservoir relating to the 2011 Kirishima Shinmoe-dake eruption-charging, discharging and recharging process inferred from GPS measurements. Earth Planets Space 65:505-515, doi:10.5047/eps.2013.05.017

Nakazawa T, Nishimura A, Iryu Y, Yamada T, Shibasaki H, Shiokawa S (2008) Rapid subsidence of the Kikai Seamount inferred from drowned Pleistocene coral limestone: implication for subduction of the Amami Plateau, northern Philippine Sea. Mar Geol 247(1):35-45, doi:10.1016/j.margeo.2007.08.004

Nishimura S, Hashimoto M, Ando M (2004) A rigid block rotation model for the GPS derived velocity field along the Ryukyu arc. Phys Earth Planet Inter 142:185-203, doi:10.1016/j.margeo.2003.12.014

Nishimura T, Matsuzawa T, Obara K (2013) Detection of short-term slow slip events along the Nankai Trough, southwest Japan, using GNSS data. J Geophys Res Solid Earth 118:3112-3125, doi:10.1002/jgrb.50222

Nishimura T, Sato M, Sagiya T (2014) Global Positioning System (GPS) and GPS-Acoustic observations: insight into slip along the subduction zones around Japan. Annu Rev Earth Planet Sci 42:653-674, doi:10.1146/annurevearth-06313-054614

Obara K (2002) Nonvolcanic deep tremor associated with subduction in southwest Japan. Science 296:1679-1681, doi:10.1126/science.1070378

Obara K (2010) Phenomenology of deep slow earthquake family in southwest Japan: spatiotemporal characteristics and segmentation. J Geophys Res 115:B00A25, doi:10.1029/2008JB006048

Obara K (2011) Characteristics and interactions between non-volcanic tremor and related slow earthquakes in the Nankai subduction zone, southwest Japan. J Geophys Res 52:229-248, doi:10.1016/j.jog.2011.04.002

Obara K, Hirose H (2006) Non-volcanic deep low-frequency tremors accompanying slow slips in the southwest Japan subduction zone. Tectonophys 417:33-51, doi:10.1016/j.tecto.2005.04.013

Obara K, Sekine S (2009) Characteristic activity and migration of episodic tremor and slow-slip events in central Japan. Earth Planets Space 61:853-862

Okada Y (1985) Surface deformation due to shear and tensile faults in a half-space. Bull Seismol Soc Am 75:1135-1154

Ozawa S (2014) Shortening of recurrence interval of Boso slow events in Japan. Geophys Res Lett 41:2762-2768, doi:10.1002/2014GL060072 
Ozawa S, Murakami M, Tada T (2001) Time-dependent inversion study of the slow thrust event in the Nankai trough subduction zone, southwestern Japan. J Geophys Res 106(B1):787-802, doi:10.1029/2000JB900317

Ozawa S, Suito H, Tobia M (2007) Occurrence of quasi-periodic slow-slip off the east coast of the Boso peninsula, Central Japan. Earth Planets Space 59:1241-1245

Ozawa S, Nishimura T, Suito H, Kobayashi T, Tobita M, Imakiire T (2011) Coseismic and postseismic slip of the 2011 magnitude-9 Tohoku-Oki earthquake. Nature 475:373-376, doi:10.1038/nature10227

Ozawa S, Yarai H, Imakiire T, Tobita M (2013) Spatial and temporal evolution of the long-term slow slip in the Bungo Channel, Japan. Earth Planets Space 65:67-73, doi:10.5047/eps.2012.06.009

Park JO, Hori T, Kaneda Y (2009) Seismotectonic implications of the Kyushu-Palau ridge subducting beneath the westernmost Nankai forearc. Earth Planets Space 61:1013-1018

Rogers G, Dragert H (2003) Episodic tremor and slip on the Cascadia subduction zone: the chatter of silent slip. Science 300:1942-1943, doi:10.1126/ science. 1084783

Schwartz SY, Rokosky JM (2007) Slow slip events and seismic tremor at circum-Pacific subduction zones. Rev Geophys 45:RG3004, doi:10.1029/ 2006RG000208

Sekine S, Hirose H, Obara K (2010) Along-strike variations in short-term slow slip events in the southwest Japan subduction zone. J Geophys Res 115:B00A27, doi:10.1029/2008JB006059

Sella GF, Dixon TH, Mao A (2002) REVEL: a model for recent plate velocities from space geodesy. J Geophys Res 107(B4), doi:10.1029/2000JB000033

Shelly DR, Beroza GC, Ide S (2007) Non-volcanic tremor and low-frequency earthquake swarms. Nature 446:305-307, doi:10.1038/nature05666

Szeliga W, Melbourne T, Santillan M, Miller M (2008) GPS constraints on 34 slow slip events within the Cascadia subduction zone, 1997-2005. J Geophys Res 113:B04404, doi:10.1029/2007JB004948

Wallace LM, Ellis S, Miyao K, Miura S, Beavan J, Goto J (2009) Enigmatic, highly active left-lateral shear zone in southwest Japan explained by aseismic ridge collision. Geology 37:143-146, doi:10.1130/G25221A.1

Wallace LM, Beavan J, Bannister S, Williams C (2012) Simultaneous long-term and short-term slow slip events at the Hikurangi subduction margin, New Zealand: implications for processes that control slow slip event occurrence, duration, and migration. J Geophys Res 117:B11402, doi:10.1029/2012JB009489

Wang K, Bilek SL (2011) Do subducting seamounts generate or stop large earthquakes? Geology 39:819-822, doi:10.1130/G31856.1

Wang K, Bilek SL (2014) Fault creep caused by subduction of rough seafloor relief. Tectonophys 610:1-24, doi:10.1016/j.tecto.2013.11.024

Wdowinski S, Bock Y, Zhang J, Fang P, Genrich J (1997) Southern California permanent GPS geodetic array: spatial filtering of daily positions for estimating coseismic and postseismic displacements induced by the 1992 Landers earthquake. J Geophys Res 102(B8):18057-18070, doi:10.1029/ 97JB01378

Wech AG, Bartlow NM (2014) Slip rate and tremor genesis in Cascadia. Geophys Res Lett 41:392-398, doi:10.1002/2013GL058607

Yabe S, Ide S (2013) Repeating deep tremors on the plate interface beneath Kyushu, southwest Japan. Earth Planet Space 65:17-23, doi:10.5047/ eps.2012.06.001

Yagi Y, Kikuchi M, Sagiya T (2001) Co-seismic slip, post-seismic slip, and aftershocks associated with two large earthquakes in 1996 in Hyuga-nada, Japan. Earth Planets Space 53:793-803

Yarai H, Ozawa S (2013) Quasi-periodic slow slip events in the afterslip area of the 1996 Hyuga-nada earthquakes, Japan. J Geophys Res Solid Earth 118:2512-2527, doi:10.1002/jgrb.50161

Yoshioka S, Toda M, Nakajima J (2008) Regionality of deep low-frequency earthquakes associated with subduction of the Philippine Sea plate along the Nankai Trough, southwest Japan. Earth Planet Sci Lett 272:189-198, doi:10.1016/j.epsl.2008.04.039

doi:10.1186/s40645-014-0022-5

Cite this article as: Nishimura: Short-term slow slip events along the Ryukyu Trench, southwestern Japan, observed by continuous GNSS. Progress in Earth and Planetary Science 2014 1:22

\section{Submit your manuscript to a SpringerOpen ${ }^{\odot}$ journal and benefit from:}

- Convenient online submission

- Rigorous peer review

- Immediate publication on acceptance

- Open access: articles freely available online

- High visibility within the field

- Retaining the copyright to your article

Submit your next manuscript at $\gg$ springeropen.com 